Supporting Information

\title{
High Performance Poly(styrene- $b$-diene- $b$-styrene) Triblock Copolymers From a Hydrocarbon-Soluble and Additive-Free Dicarbanionic Initiator
}

\author{
Rachid Matmour, Arvind S. More, Prakash P. Wadgaonkar, and Yves Gnanou* \\ Laboratoire de Chimie des Polymères Organiques, ENSCPB-Université Bordeaux 1, 16 \\ Avenue Pey Berland, 33607 Pessac Cedex, France and Polymer Science and Engineering \\ Division, National Chemical Laboratory, Dr.Homi Bhabha Road, Pune-411 008, India .
}

E-mail: gnanou@enscpb.fr

Tel: +33 (0)5 400084 86; Fax: +33 (0)5 40008486

\section{Experimental Section}

Materials. Cyclohexane was dried and distilled twice over $\mathrm{CaH}_{2}$ and polystyryllithium, successively. THF was dried and distilled twice over $\mathrm{CaH}_{2}$ and sodium/benzophenone, successively. Solutions of sec-butyllithium were used for halogen-lithium exchange reaction after double titration. ${ }^{1}$ Styrene (S) and butadiene (B) were purified over $\mathrm{CaH}_{2}$ and dibutylmagnesium, and s-BuLi, respectively. Ethylene oxide was dried and distilled over Na.

Synthesis of 1-pentadecyl-3-phenoxy benzene. Into a two necked round bottom flask fitted with a Dean and Stark apparatus equipped with a reflux condenser were placed $100 \mathrm{~g}$ (0.33 mol) of 3-pentadecyl phenol, $22.06 \mathrm{~g}$ (0.39 mol) potassium hydroxide, $300 \mathrm{ml} \mathrm{N,N-}$ dimethylacetamide and $150 \mathrm{ml}$ toluene. The reaction mixture was refluxed for $7 \mathrm{~h}$ with continuous removal of by-product water. After completion of the reaction, the solvent was distilled off and the obtained potassium salt of 3-pentadecyl phenol was dried under reduced pressure. To a round bottom flask containing $111 \mathrm{~g}$ (0.32 mol) potassium salt of 3-pentadecyl phenol were added $50.88 \mathrm{~g}(0.32 \mathrm{~mol})$ of bromobenzene, $2.22 \mathrm{~g} \mathrm{Cu}$ powder (2 wt \% of potassium salt of 3-pentadecyl phenol) and $150 \mathrm{ml} \mathrm{N,N-dimethylacetamide.} \mathrm{The} \mathrm{reaction}$ mixture was heated at $150^{\circ} \mathrm{C}$ for $8 \mathrm{~h}$. The obtained dark colored reaction mixture was poured into $500 \mathrm{ml}$ water; and copper salts were removed by filtration; The filtrate was extracted with ethyl acetate ( $3 \times 400 \mathrm{ml}$ ), The ethyl acetate solution was washed with water, followed by brine solution and again with water and dried over sodium sulfate. Solvent evaporation 
yielded crude 1-pentadecyl-3-phenoxy benzene. Pure 1-pentadecyl-3-phenoxy benzene was obtained by silica gel (60-120 mesh) column chromatography (pet ether). Yield 70 g (57 \%). ${ }^{1} \mathrm{H}$ NMR $\left(\mathrm{CD}_{2} \mathrm{Cl}_{2}\right): \delta$ 8.0-6.5 (m, 9H, ArH), 2.6 (m, 2H, -CH $\boldsymbol{H}_{2} \mathrm{Ar}$ ), 1.7-1.0 (b, 26H, -CH $\boldsymbol{H}_{2}$ $\left.\mathrm{CH}_{3}\right), 0.8\left(\mathrm{~m}, 3 \mathrm{H},-\mathrm{CH}_{3}\right)$.

Synthesis of 1-bromo-(4-bromophenoxy)-2-pentadecyl benzene (1). Into a three necked round bottom flask equipped with a magnetic stirring bar, a reflux condenser, a dropping funnel and a thermometer were placed $25 \mathrm{~g}(0.066 \mathrm{~mol})$ of 1-pentadecyl-3-phenoxy benzene and $150 \mathrm{ml}$ dichloromethane. To the reaction mixture was added dropwise $22.08 \mathrm{~g}$ (0.14 mol) of bromine at a temperature between $-5^{\circ}$ to $0^{\circ} \mathrm{C}$ over a period of 15 minutes while the reaction mixture was protected from light. After completion of bromine addition, the reaction mixture was stirred at the same temperature for $1 \mathrm{~h}$ and then refluxed overnight. The excess bromine and hydrobromic acid were neutralized with aqueous $10 \% \mathrm{NH}_{3}(100 \mathrm{ml})$. The organic layer separated was washed with water, followed by brine solution and again with water. The dichloromethane solution was dried over sodium sulfate, filtered and the solvent was removed on a rotary evaporator. The crude product was purified by silica gel (60-120 mesh) column chromatography to obtain pure 1-bromo-(4-bromophenoxy)-2-pentadecyl benzene. Yield $30 \mathrm{~g}$ (84\%). ${ }^{1} \mathrm{H}$ NMR $\left(\mathrm{CD}_{2} \mathrm{Cl}_{2}\right)$ : $\delta$ 8.0-6.5 (m, 7H, ArH), 2.6 (m, 2H, -CH $\left.-\mathrm{Ar}\right), 1.7-1.0$ (b, 26H, $\left.\mathrm{CH}_{2}-\mathrm{CH}_{3}\right), 0.8\left(\mathrm{~m}, 3 \mathrm{H},-\mathrm{CH}_{3}\right)$.

Polystyrene and polybutadiene telechelics preparation. In a flask, $145 \mathrm{mg}\left(2.69 * 10^{-4}\right.$ mol) of 1 was freeze-dried. $5 \mathrm{~mL}$ of cyclohexane were added to make a precursor solution concentration of $5.3 * 10^{-2}$ mol. $\mathrm{L}^{-1}$. $0.83 \mathrm{~mL}\left(1.08 * 10^{-3} \mathrm{~mol}\right)$ of sec-butyllithium at a concentration of $1.3 \mathrm{M}$ was added to the solution. After 20 minutes of reaction, the monomer was added dropwise. After the total consumption of the monomer, an excess of ethylene oxide was added. The polymerization, which was entirely carried out under inert atmosphere, was deactivated by degassed methanol. The linear polymer was precipitated using methanol. Dihydroxy-terminated linear polybutadiene: $M_{\mathrm{n}}($ SEC in THF $)=6,200 \mathrm{~g} / \mathrm{mol} ; M_{\mathrm{w}} / M_{\mathrm{n}}=1.13$. ${ }^{1} \mathrm{H}$ NMR $\left(\mathrm{CD}_{2} \mathrm{Cl}_{2}\right): \delta$ 8.0-6.9 (m, 7H, aromatic resonances from the difunctional initiator), 5.4 (m, 3H, $\mathrm{CH}_{2}-\mathrm{CH}=\mathrm{CH}-\mathrm{CH}_{2}-$ and $\mathrm{CH}_{2}=\mathrm{CH}-\mathrm{CH}-$ ), 4.9 (s, 2H, $\mathrm{CH}_{2}=\mathrm{CH}-\mathrm{CH}-$ ), 3.6 (s, 4H, $-\mathrm{CH}_{2}-\mathrm{OH}$ ), 2.0 (b, 5H, $\mathrm{CH}_{2}-\mathrm{CH}=\mathrm{CH}-\mathrm{CH}_{2}-$ and $\mathrm{CH}_{2}=\mathrm{CH}-\mathrm{CH}-$ ), 1.2 (b, $\left.\mathrm{CH}_{2}=\mathrm{CH}-\mathrm{C}(\mathrm{R}) \mathrm{H}-\mathrm{CH}_{2}-\right), 0.9\left(\mathrm{~b}, 3 \mathrm{H},-\mathrm{CH}_{3}\right)$.

Synthesis of SBS triblock copolymer. In a flask, $75 \mathrm{mg}\left(1.39 * 10^{-4} \mathrm{~mol}\right)$ of 1 was freezedried. $3 \mathrm{~mL}$ of cyclohexane to obtain a precursor solution at the concentration of $5.3^{*} 10^{-2}$ $\mathrm{mol} / \mathrm{L}$ were introduced. $0.43 \mathrm{~mL}\left(5.56 * 10^{-4} \mathrm{~mol}\right)$ of sec-butyllithium at the concentration of 
1.3 $\mathrm{M}$ was added to the solution. After 20 minutes of reaction, butadiene was added dropwise at $5^{\circ} \mathrm{C}$. After 24 hours of polymerisation, the reaction medium was diluted with a solution of cyclohexane/THF (100/1 in volume). Then styrene was added and the colour of the medium changed instantaneously from the characteristic yellow colour of polybutadienyllithium carbanions to the orange colour of polystyryllithium carbanions. The polymerization was entirely carried out under inert atmosphere and let for 12 hours at room temperature. Finally, the polymerization was deactivated by degassed methanol. The triblock copolymer was precipitated in methanol. SBS triblock copolymer: $M_{\mathrm{n}}\left({ }^{1} \mathrm{H}\right.$ NMR in $\left.\mathrm{CDCl}_{3}\right)=93,500 \mathrm{~g} / \mathrm{mol}$; $M_{\mathrm{w}} / M_{\mathrm{n}}=1.2 .{ }^{1} \mathrm{H} \mathrm{NMR}\left(\mathrm{CDCl}_{3}\right): 8.0-6.9(\mathrm{~m}, 7 \mathrm{H}$, aromatic resonances from the difunctional initiator and the styrene units), $5.4\left(\mathrm{~m}, 3 \mathrm{H}, \mathrm{CH}_{2}-\mathrm{CH}=\mathrm{CH}-\mathrm{CH}_{2}-\right.$ and $\mathrm{CH}_{2}=\mathrm{CH}-\mathrm{CH}-$ ), 4.9 (s, 2H, $\mathrm{CH}_{2}=\mathrm{CH}-\mathrm{CH}-$ ), $3.6\left(\mathrm{~s}, 4 \mathrm{H},-\mathrm{CH}_{2}-\mathrm{OH}\right), 2.0$ (b, 5H, $\mathrm{CH}_{2}-\mathrm{CH}=\mathrm{CH}-\mathrm{CH}_{2}-$ and $\mathrm{CH}_{2}=\mathrm{CH}-\mathrm{CH}-$ ), $1.2\left(\mathrm{~b}, \mathrm{CH}_{2}=\mathrm{CH}-\mathrm{C}(\mathrm{R}) \mathrm{H}-\mathrm{CH}_{2}-\right)$, 0.9 (b, 3H,- $\left.\mathrm{CH}_{3}\right)$.

Instrumentation. High-purity argon (>99.5\%) was rigorously dried and deoxygenated by passage through a column containing vermiculite. ${ }^{1} \mathrm{H}$ NMR spectra were recorded on a Brüker AC400@ spectrometer using $\mathrm{CDCl}_{3}$ and $\mathrm{CD}_{2} \mathrm{Cl}_{2}$ as deuterated solvent. Chemical shifts are reported in ppm $(\delta)$ downfield from tetramethylsilane (TMS) and referenced to residual protio solvent. Apparent molar masses were determined with a size exclusion chromatography (SEC) equipped with four TSK-gel columns (7,8 x $30 \mathrm{~cm}, 5 \mu \mathrm{m}, \mathrm{G} 2000,3000,4000$ and 5000 HR with pore sizes of $250,1,500,10,000$ and $100,000 \AA$, respectively) and THF as the mobile phase (1 mL/min). This instrument was equipped with a refractive index (RI) (Varian RI-4) and UV-vis (Varian 2550 variable $\lambda$ ) detectors. The SEC was calibrated using linear polystyrene samples.

(1) Suffert, J. J. Org. Chem. 1989, 54, 509. 

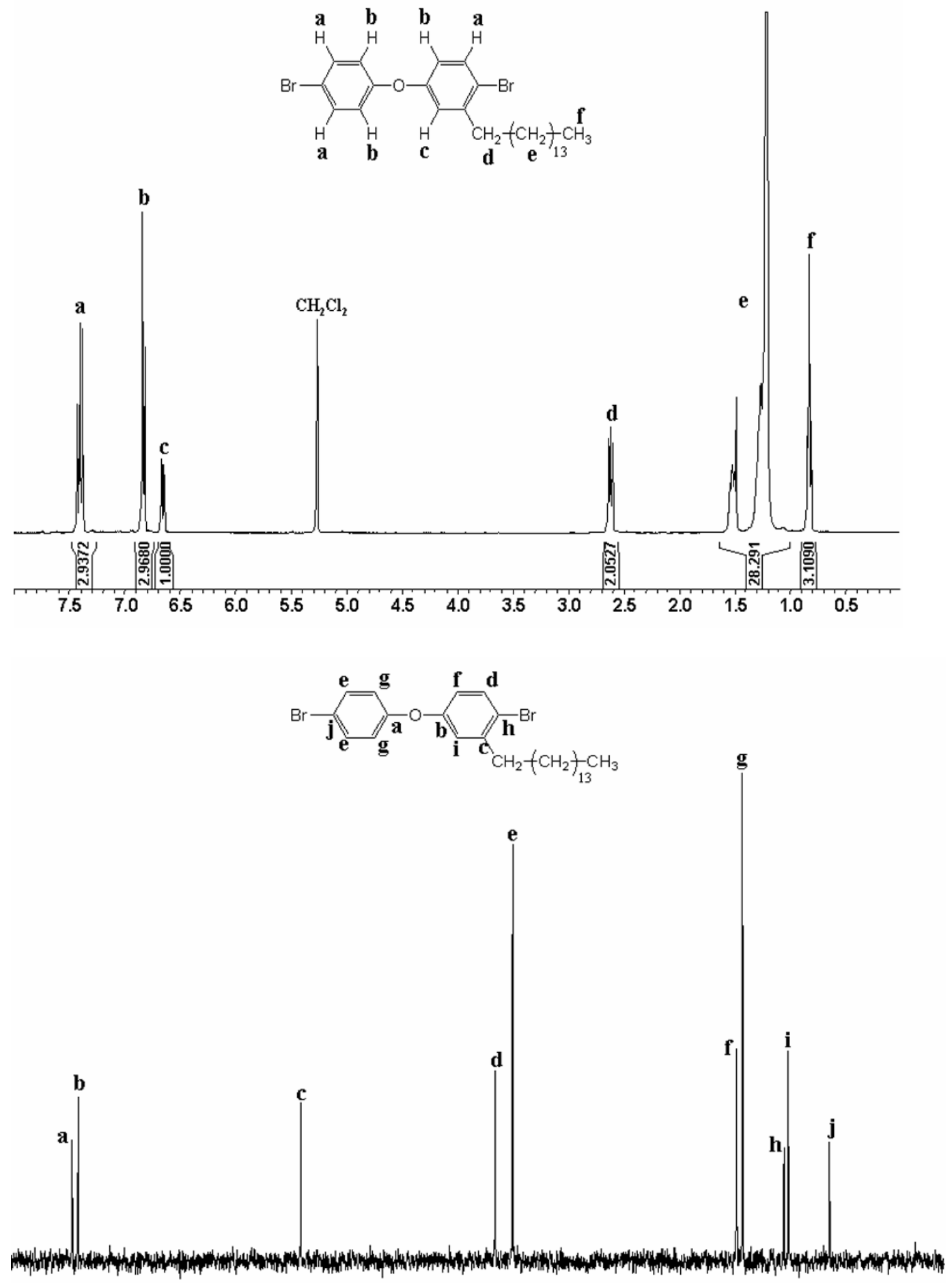

$\begin{array}{llllllllllllllllllllllll}158 & 156 & 154 & 152 & 150 & 148 & 146 & 144 & 142 & 140 & 138 & 136 & 134 & 132 & 130 & 128 & 126 & 124 & 122 & 120 & 118 & 116 & 114 & 112\end{array}$ $1-\delta(\mathrm{ppm})$

Figure S1. ${ }^{1} \mathrm{H}$ and ${ }^{13} \mathrm{C}$ NMR spectra $\left(\mathrm{CD}_{2} \mathrm{Cl}_{2}, 400 \mathrm{MHz}\right)$ of 1-bromo-4-(4'-bromophenoxy)-2pentadecyl benzene (1). 


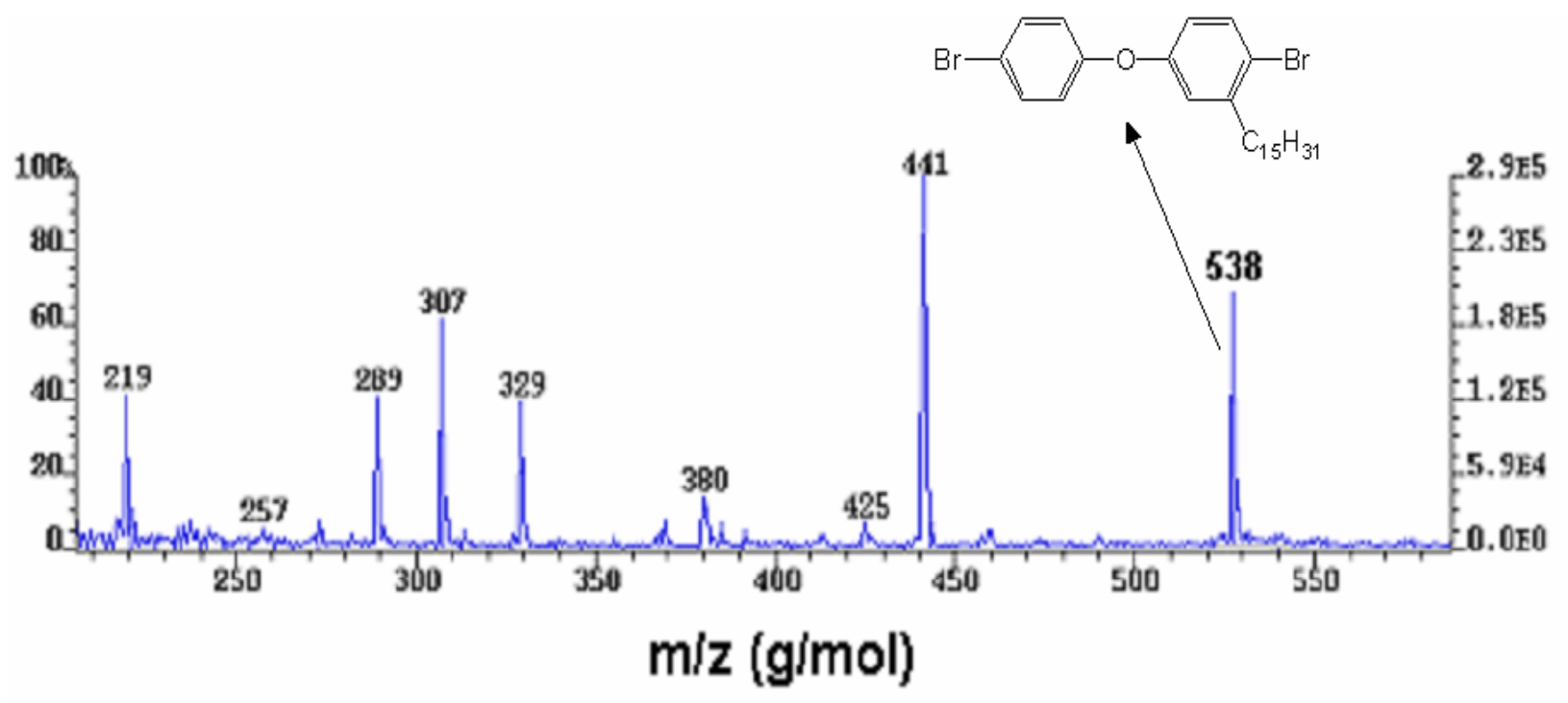

Figure S2. Mass spectrum of 1-bromo-4-(4'-bromophenoxy)-2-pentadecyl benzene (1). 

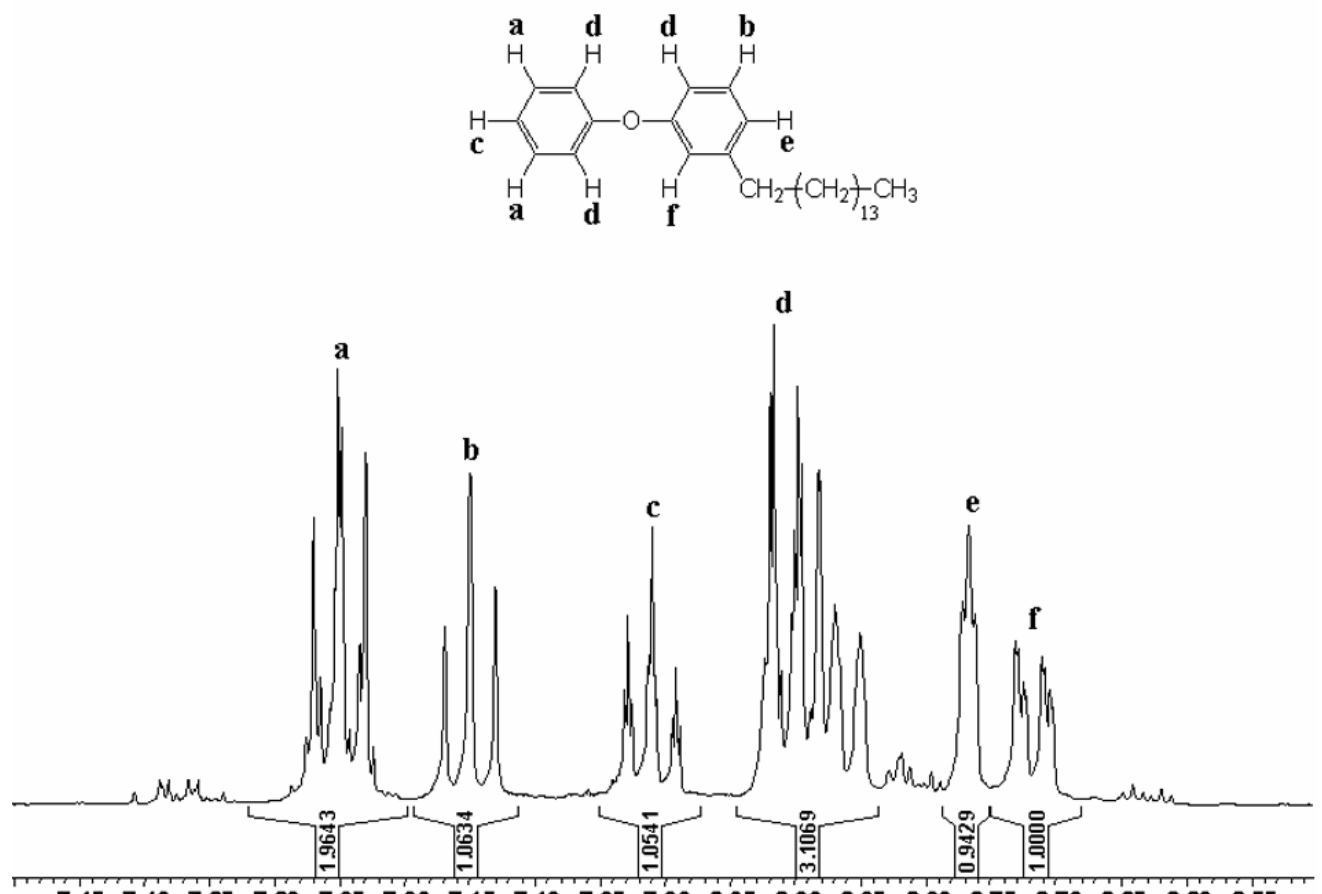

$\begin{array}{lllllllllllllllllllll}7.45 & 7.40 & 7.35 & 7.30 & 7.25 & 7.20 & 7.15 & 7.10 & 7.05 & 7.00 & 6.95 & 6.90 & 6.85 & 6.80 & 6.75 & 6.70 & 6.65 & 6.60 & 6.55\end{array}$
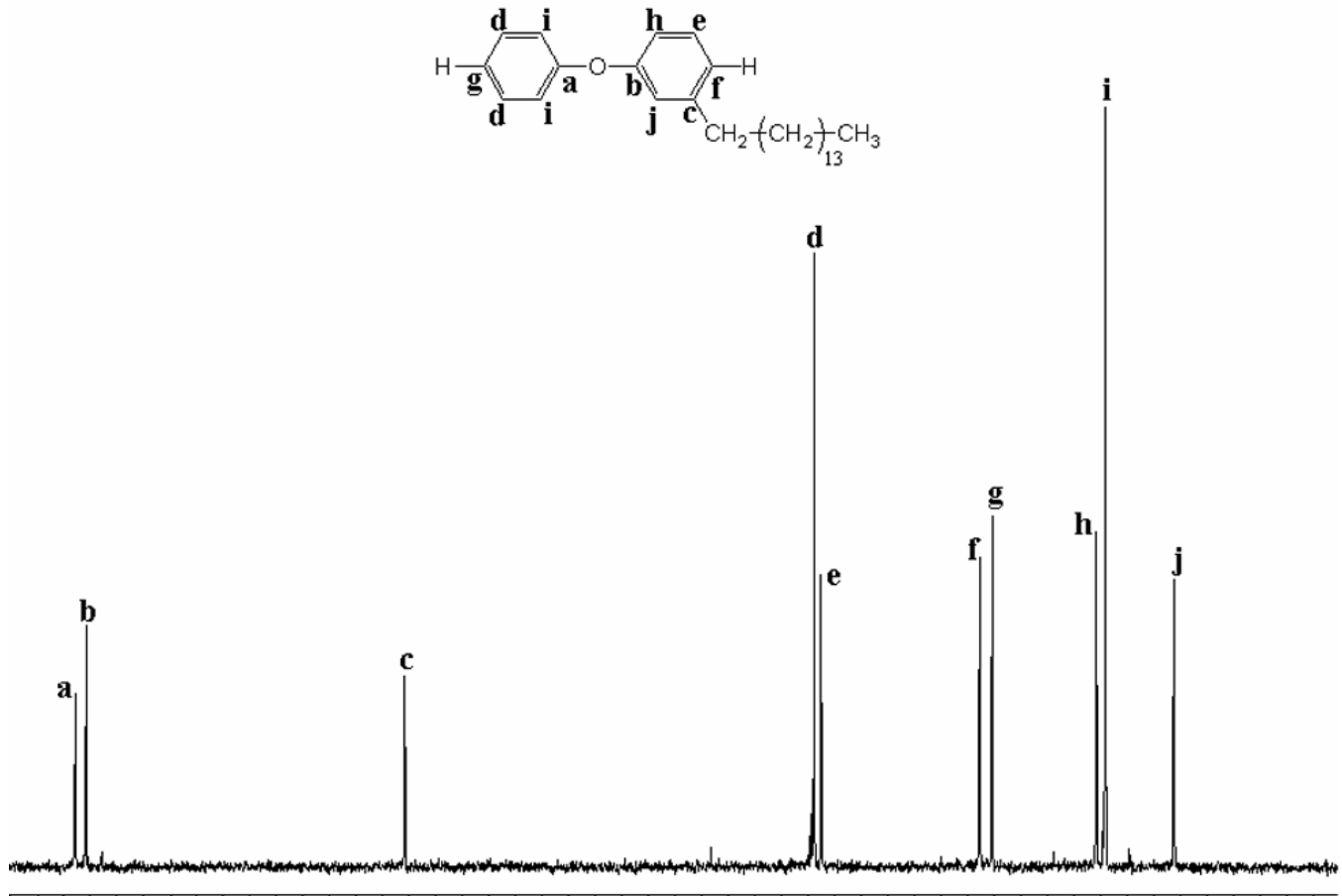

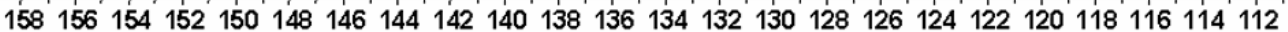
$\delta($ (ppm)

Figure S3. ${ }^{1} \mathrm{H}$ and ${ }^{13} \mathrm{C}$ NMR spectra $\left(\mathrm{CD}_{2} \mathrm{Cl}_{2}, 400 \mathrm{MHz}\right)$ of the protonated version of $\mathbf{1}$, after methanolysis. 


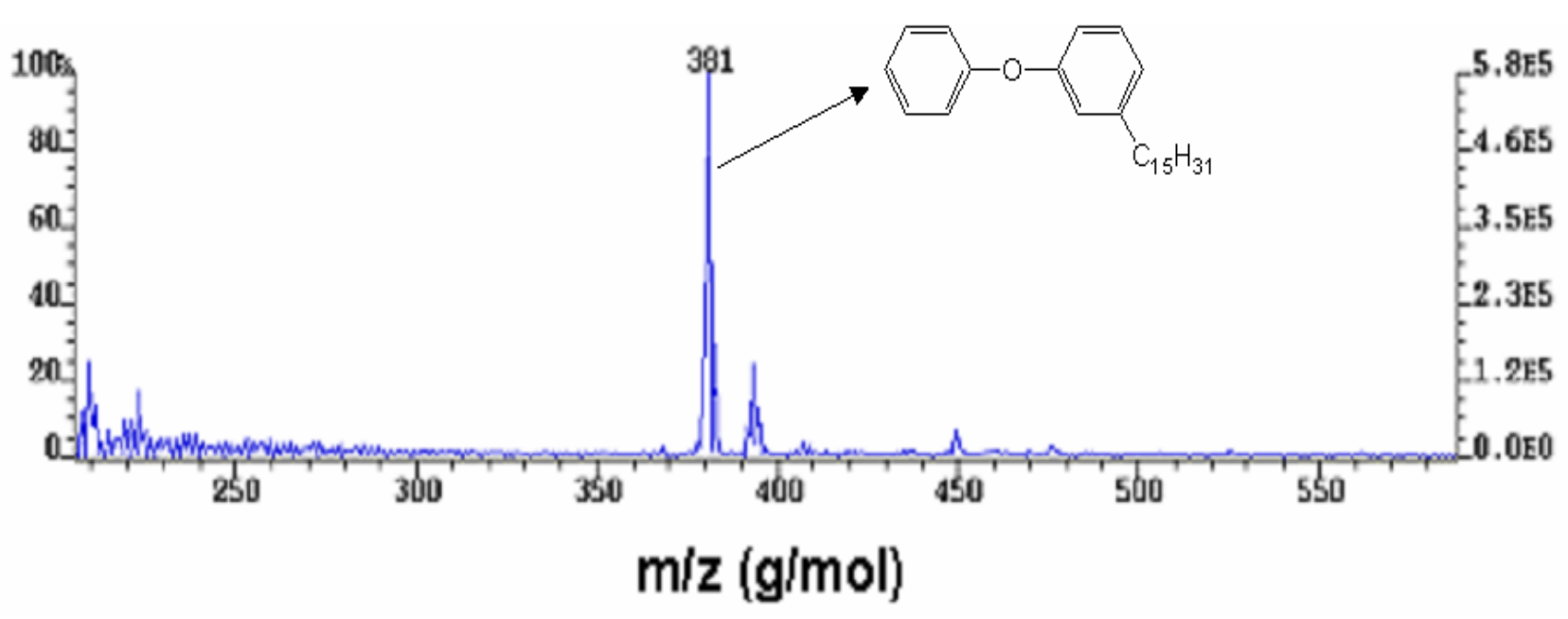

Figure S4. Mass spectrum of the protonated version of 1' after methanolysis. 

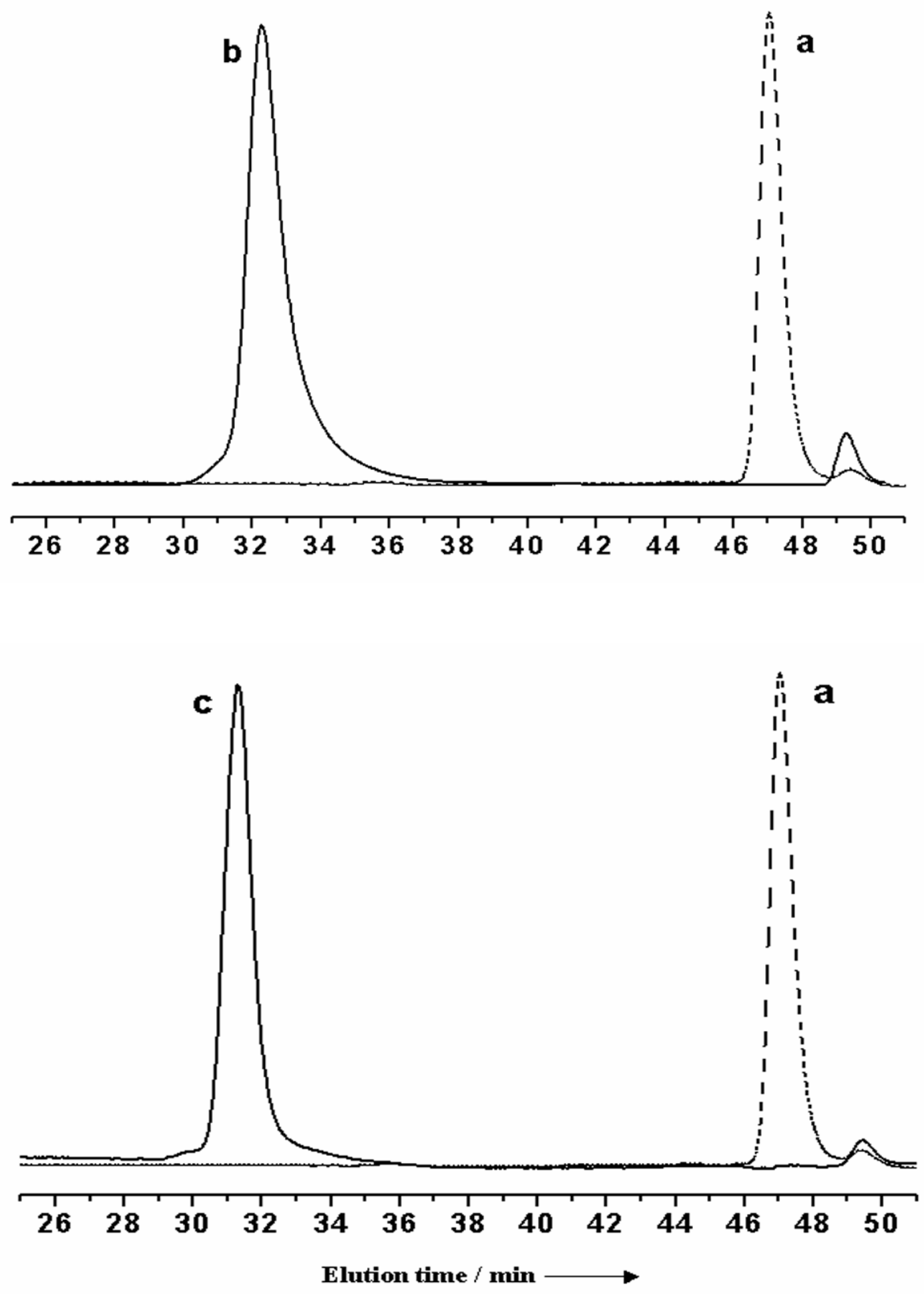

Figure S5. SEC eluograms of $(\mathrm{PS})_{2}$ difunctional polystyrene and $(\mathrm{PB})_{2}$ difunctional polybutadiene : a) Protonated version of 1'; b) Linear polystyrene (Run 2, Table S1); and c) Linear polybutadiene (Run 7, Table S1). 

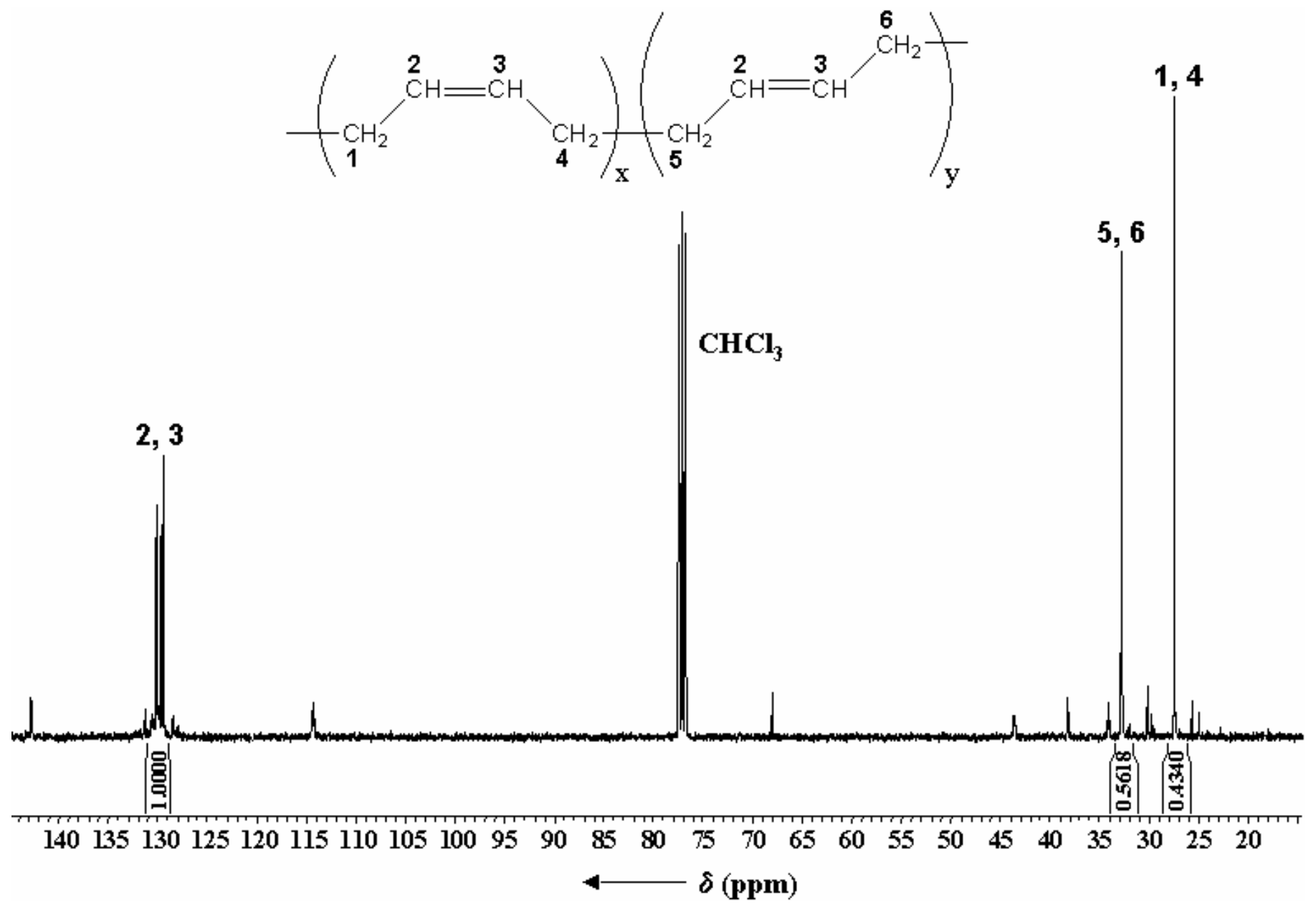

Figure S6. ${ }^{13} \mathrm{C}$ NMR spectrum $\left(\mathrm{CDCl}_{3}, 400 \mathrm{MHz}\right)$ of a $\alpha, \omega$-dihydroxy-terminated polybutadiene (Run 6, Table S1). 


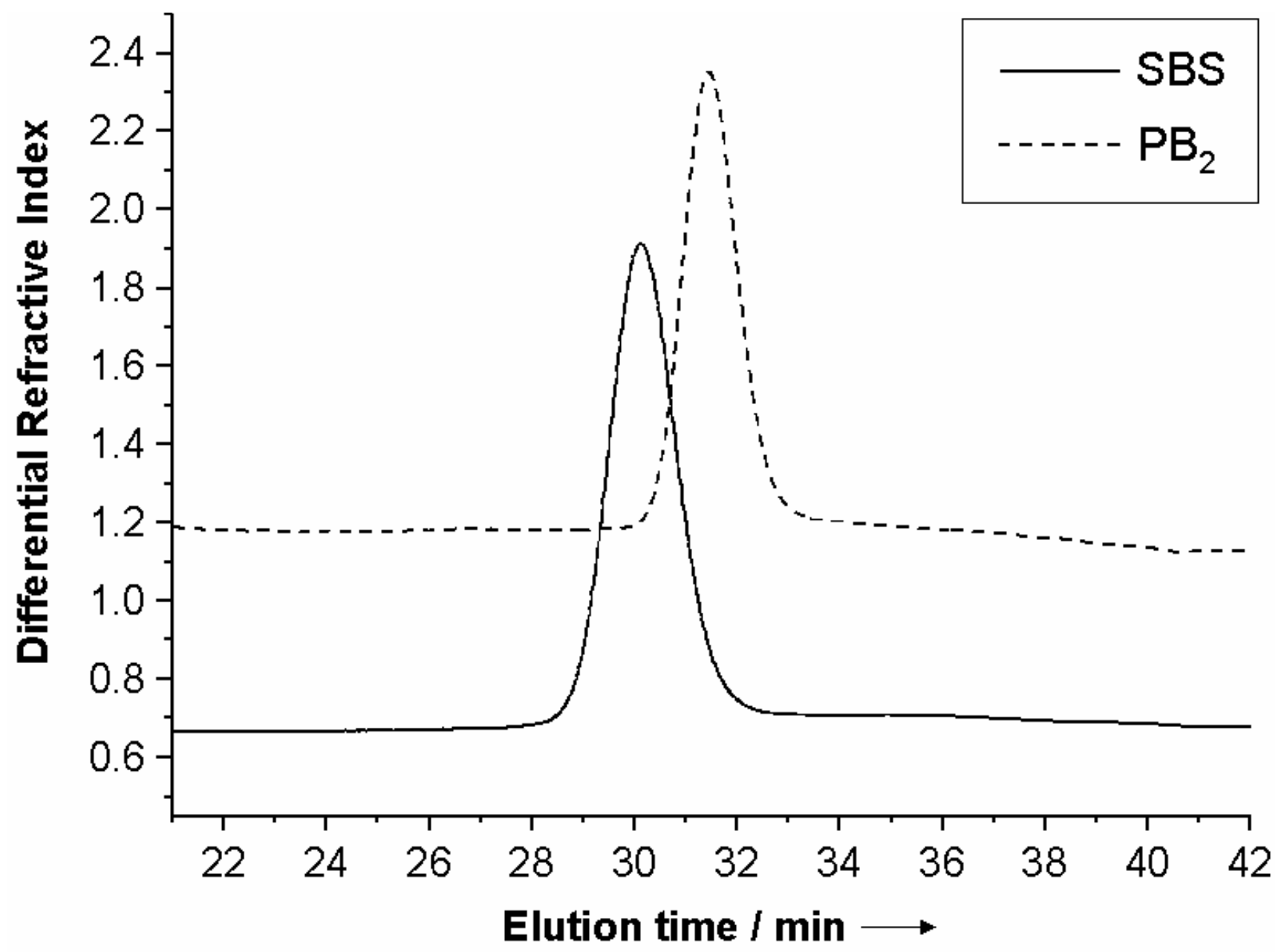

Figure S7. SEC eluograms monitoring the formation of a SBS triblock copolymer initiated in cyclohexane with 1' (Run 11, Table S2). 


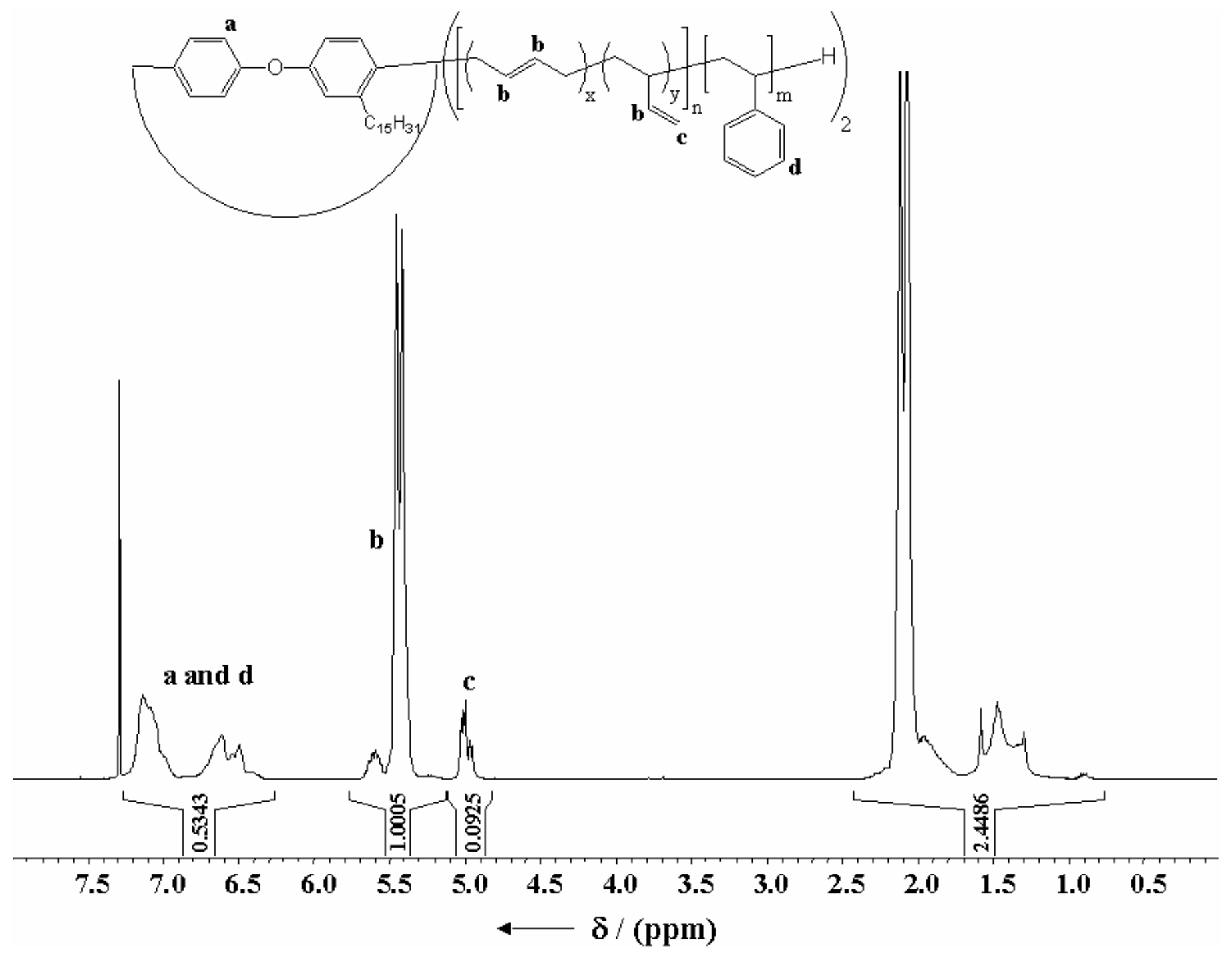

Figure S8. ${ }^{1} \mathrm{H}$ NMR spectrum $\left(\mathrm{CDCl}_{3}, 400 \mathrm{MHz}\right)$ of a SBS triblock copolymer (Run 11, Table S1). 


\section{Schemes}

Scheme S1. Synthesis of 1-bromo-4-(4'-bromophenoxy)-2-pentadecyl benzene (1).

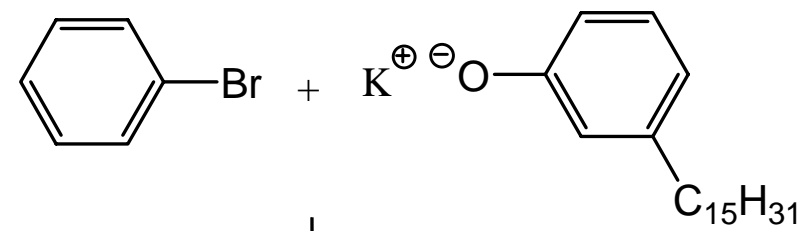

Cu Powder yield $=57 \%$
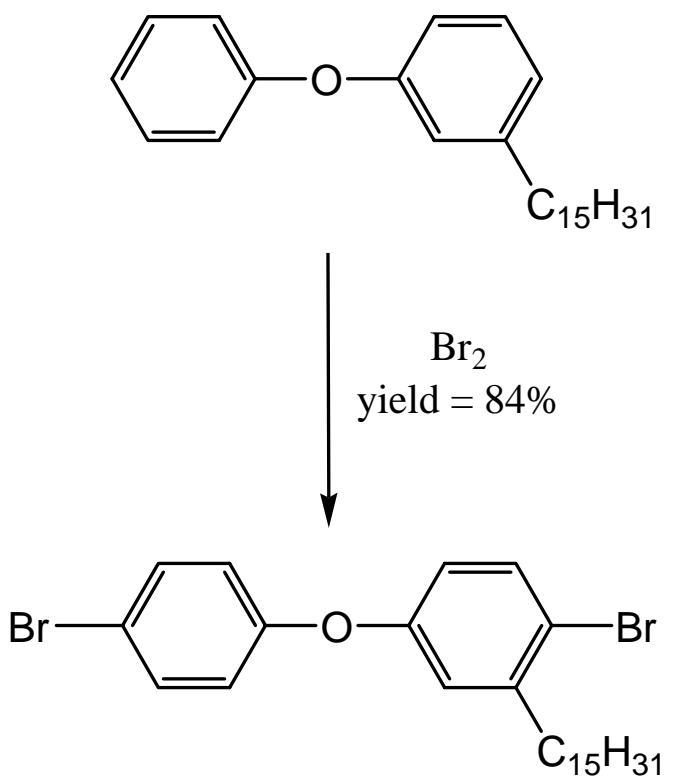


\section{Table}

Table S2. Mechanical properties of SBS triblock copolymers initiated by 1'.

\begin{tabular}{|c|c|c|c|c|c|c|c|}
\hline \multicolumn{2}{|c|}{ Polybutadiene } & \multicolumn{3}{|c|}{ SBS } & \multirow{2}{*}{$\begin{array}{c}\text { 1,4-units }{ }^{\mathrm{c}} \\
\text { (\%) }\end{array}$} & \multirow{2}{*}{$\begin{array}{l}\text { Ultimate } \\
\text { tensile strength } \\
(\mathrm{MPa})\end{array}$} & \multirow{2}{*}{$\begin{array}{c}\text { Elongation at } \\
\text { break (\%) }\end{array}$} \\
\hline$\overline{M_{n}} \mathrm{~b}$ & $\overline{M_{w}} / \overline{M_{n}} \mathrm{~b}$ & $\overline{M_{n}} \mathrm{~b}$ & $\overline{M_{n}}{ }^{c}$ & $\overline{M_{w}} / \overline{M_{n}} \mathrm{~b}$ & & & \\
\hline 6200 & 1.13 & 20400 & 18300 & 1.2 & 86 & - & - \\
\hline 43700 & 1.1 & 78300 & 60300 & 1.1 & 90 & 29.5 & 900 \\
\hline 67400 & 1.1 & 110900 & 93500 & 1.2 & 91 & 33.8 & 1000 \\
\hline \multicolumn{8}{|c|}{$\begin{array}{l}\text { a Butadiene polymerisation was initiated in cyclohexane with } \mathbf{1}^{\prime}\left(\left[\mathrm{Li}^{+}\right]=5.3 * 10^{-2} \mathrm{M}\right) \text {. } \\
\text { b Determined by SEC in THF using a refractometric detector. A conversion factor of } 0.55 \text { was } \\
\text { used for the calculation of the polybutadiene molar mass. }{ }^{\mathrm{c}} \text { Determined by }{ }^{1} \mathrm{H} \text { NMR from the } \\
\text { molar mass of the polybutadiene block, assuming } 100 \% \text { efficiency in the initiation of the } \\
\text { second block. }\end{array}$} \\
\hline
\end{tabular}


